\title{
INCLUSIÓN Y EXCLUSIÓN EN LA ESCUELA MODERNA ARGENTINA: UNA PERSPECTIVA POSTESTRUCTURALISTA
}

\author{
INÉS DUSSEL \\ Facultad Latinoamericana de Ciencias Sociales - Argentina \\ idussel@flacso.org.ar \\ RESUMEN
}

Este artículo se propone revisar la historia de la escuela moderna en América Latina, utilizando conceptos de las teorías postestructuralistas sobre la identidad y su constitución paradójica. Poniendo en cuestión la hipótesis de que la expansión de la escuela fue un movimiento ascendente y progresivo, analiza cómo se construyóla equivalencia discursiva entre igualdad y homogeneización en el espacio educativo latinoamericano, y cómo esta equivalencia congeló a las diferencias como amenaza o deficiencia. A partir de dos ejemplos (las pedagogías normalizadoras y el uso de delantales en las escuelas argentinas), discute los efectos de la producción de estas identidades, y plantea desafíos para una rearticulación más democrática de la propuesta escolar. POSMODERNO-IDENTIDAD-DEMOCRATIZACIÓNDELAEDUCACIÓN-ARGENTINA

\section{ABSTRACT}

INCLUSIONAND EXCLUSIONINARGENTINA'S MODERN SCHOOL: APOSTSTRUCTURALIST VIEW. This article revisits the history of modern schooling in Latin America, using concepts provided by poststructuralist theories on identity and its paradoxical constitution. Questioning the hypothesis that the expansion of schooling was a progressive, ascending movement, the article analizes how a peculiar discursive equivalence between equality and homogenization was constructed in the Latin American educational space, and how this equivalence froze difference as threat or defficiency. Using two examples (normalizing pedagogies and the wearing of uniforms in Argentinean schools), it discusses the effects of producing such identities, and posits the challenges faced towards a more democratic rearticulation of schooling.

POST-MODERN - IDENTITY - DEMOCRATIZATION OF EDUCATION - ARGENTINA

Este artículo fue publicado anteriormente en la revista Papeles, de la Universidad de Granada, Espanha (Dussel, 2003). 
En los últimos años ha habido un creciente interés en la escuela. Reformas gubernamentales de amplio alcance, informes de organismos privados, trabajos académicos e iniciativas docentes concuerdan en que la escuela está en el centro de la solución a problemas sociales tales como la exclusión, el desempleo, la violencia y la discriminación (Tyack, Cuban, 1995). Se nos dice que la educación va a conducir al desarrollo individual y al mejoramiento social una vez que los políticos y administradores de la educación consigan implementar y extender los principios fundacionales de la educación moderna: igualdad, ilustración, libertad (Hunter, 1998). El desafío actual sería encontrar el método y la organización adecuadas para llevar a cabo estos principios.

Aunque este optimismo sobre los efectos de la educación es bastante viejo de hecho, es hijo directo y dilecto de las reformas escolares de los siglos $X I X$ y $X X$ (Kliebard, 1986; Santoni Rugiu, 1980) -, puede decirse que goza de buena salud. Sin embargo, cada vez hay más señalamientos sobre la necesidad de cuestionar estos principios y modos de razonamiento de la escuela moderna, ya que ellos serían parte del problema antes que su solución (Donald, 1992; Hunter, 1998; Popkewitz, | 1991, 1998). Estos trabajos críticos nos han enseñado que la escolaridad debe ser entendida como una práctica histórica que ha cristalizado en un marco institucional particular, contingente y arbitrario, y que ha servido múltiples propósitos, que no son necesariamente los mismos proclamados por la escuela de masas. Más aún, ellos argumentan que las nociones de "libertad" e "igualdad" fueron definidas de tal forma que han llevado a la obediencia y la exclusión sociales. Por ello, si deseamos pensar y cuestionar las causas de una persistente y extendida injusticia social y educativa, probablemente debamos comenzar por interrogar este "relato sobre la inclusión", es decir, la narrativa que sostiene que la expansión del sistema escolar moderno es la única manera, y la mejor, de ilustrar al pueblo y democratizar las sociedades.

Tal como lo señala Popkewitz (199|, p.4), la cuestión de la inclusión es un proyecto político fundamental en sociedades que han excluído sistemática y categóricamente a grupos sociales. No quiero en esta ponencia menospreciar ni deslegitimar estas luchas. Sin embargo, tal como lo dice este autor, la manera en que hemos concebido la inclusión quizás sea el "crimen" que debemos investigar, y no sólo la falta de "acceso" de algunas poblaciones a la institución escolar. Así, considero que las preguntas que deberían guiar nuestra reflexion sobre la exclusión educativa en nuestras sociedades son las siguientes: ien qué sistema escolar queremos incluir a todos? ¿No es acaso la organización actual de la escuela la que ha producido 
buena parte de las exclusiones? ¿Cómo puede re-examinarse esta institución, conservando el sueño de educar a todos pero evitando reproducir las mismas injusticias?

Para articular estas preguntas y sugerir algunas respuestas, propongo en este artículo una problematización de las nociones de inclusión y exclusión a través de un recorrido por la historia de la escuela moderna en América Latina y particularmente en la Argentina. Creo que los dilemas de la escuela y sus modos de accionar en esta región tienen mucho que aportar al debate español contemporáneo, también signado por pesadas herencias y con iguales esperanzas de construir un futuro mejor.

\section{INCLUSIÓN/EXCLUSIÓN Y LA CONSTITUCIÓN PARADÓJICA DE LA IDENTIDAD}

La noción de inclusión, como ya se ha dicho, es uno de los principios fundantes de la escuela moderna. La emergencia de la institución escolar tuvo mucho que ver con la búsqueda de encontrar un método que asegurara la replicación y la uniformidad de una cierta experiencia educativa para un conjunto más grande de la población. David Hamilton (1989), por ejemplo, ha identificado el origen del término "curriculum" en la acción de algunos educadores empeñados en sistematizar el curso de estudios y convertirlo en una trayectoria más racional y ordenada para más sujetos. La idea moderna de "escuela", por otra parte, aparece en la modernidad temprana en contraposición a la educación del príncipe, guiada por un instructor y realizada en un marco principalmente doméstico y de la corte; en forma opuesta, la escuela elemental se dirige al pueblo, implica un conjunto heterogéneo de sujetos, y aunque inicialmente puede tener lugar en una iglesia o establo, conocerá una especialización creciente, tanto de sus agentes como de sus locales.

La historia de la educación tradicional, y aún la revisionista, han presentado a la escuela como la culminación de una evolución en favor de la libertad y de la ilustración colectivas. Se ha dicho, no sin algo de razón, que los pedagogos y políticos educativos, desde Comenio y su ideal pansófico hasta los planes educativos de la Revolución Francesa, han proclamado la necesidad y la importancia de garantizar el acceso de todos los individuos a la educación, enfrentándose a los sectores de privilegio que pugnaban por no extender sus beneficios.

Hay un punto, sin embargo, que debe revisarse en torno a este relato sobre la inclusión educativa. Véase por ejemplo el plan educativo de Michel de Lepelletier (apud Chevallier, Gosperrin, 197I), uno de los más radicalizados de la Revolución 
Francesa: en él, se propone que todos los niños de 5 a I I ó 12 años (según fueran niñas o varones) sin distinciones o excepciones sean educados a expensas de la República, y "que todos, bajo la santa ley de la equidad, reciban el mismo vestuario, la misma alimentación, la misma instrucción, el mismo cuidado". Los niños, educados en las "casas de la igualdad" - como se llamaría a estas instituciones educativas serían los perfectos ciudadanos de la nueva sociedad. La igualdad, en un movimiento de asociación discursiva que perduraría al menos dos siglos, se volvía equivalente a la homogeneidad, a la inclusión indiscriminada e indistinta en una identidad común, que iba a garantizar la libertad y la prosperidad general. La manera en que la escuela procesó la diversidad que recibía en sus docentes y en sus alumnos fue, salvo algunas excepciones, homogeneizarla y uniformizarla.

Conviene detenerse por un momento en esta equivalencia discursiva entre inclusión y homogeneización para analizar si podría ser de otro modo.

El movimiento de inclusión supone la integración en un "nosotros" determinado, ya sea la comunidad nacional o un grupo particular (clase social, minorías étnicas, "niños discapacitados", "niños en riesgo"). Este "nosotros" siempre implica un "ellos" que puede ser pensado como complementario o como amenazante, o aún ser invisible para la mayoría de la gente. Es decir, la inclusión en una identidad determinada supone la exclusión de otros, la definición de una frontera o límite más allá de la cual comienza la otredad. Un elemento central para definir la inclusión y la exclusión es cómo se conceptualizan la identidad y la diferencia, y cómo y a través de qué mecanismos y técnicas se establecen y operan los límites entre ellas.

Las afirmaciones precedentes pueden parecer muy comunes pero involucran un debate con tradiciones metafísicas que señalan que las identidades son productos "naturales" de las cosas y de la humanidad. Siguiendo al politólogo William Connolly, señalaremos que la identidad se constituye de forma paradójica. Todas las identidades se establecen en relación a una serie de diferencias que están socialmente reconocidas. La diferencia provee la medida contra la cual un ser puede afirmar su carácter distintivo y su solidez. El terreno en el cual afirma este carácter único es, sin embargo, inseguro y resbaladizo. Aunque no puede desechar a la diferencia para poder ser, la identidad es vulnerable a la tendencia a convertir la diferencia en una total otredad para poder así asegurar su propia certidumbre (Connolly, 1991 , p. 64). Así, "la identidad está en una relación compleja, política, con las diferencias que busca fijar", e involucra una violencia constitutiva (una relación de poder) a través de la constitución de esas diferencias. Connolly subraya que la diferencia puede ser pensada como una identidad distinta que es complementaria, negativa, o amenazante, 
o rechazarla al plano de lo impensable e invisible, y que todas estas opciones son siempre políticas, tienen efectos de poder y son efecto de relaciones de poder.

En la misma línea, la filósofa feminista Judith Butler argumenta que "cada movimiento formativo requiere e instituye sus exclusiones". Tanto como para Connolly, para ella las identidades están inscriptas en relaciones de poder desde su propia formación, distinguiendo y jerarquizando las diferencias. Butler le suma un fundamento psicoanalítico, diciendo que el "poder también opera por la forclusión de sus efectos, la producción de un 'afuera', un dominio de 'in-habitabilidad' e ininteligibilidad que limita/circunscribe el dominio de efectos inteligibles" (Butler, 1993, p. 22). Este "afuera" es lo que se congela como otredad, como alteridad irreductible, y lo que en la mayoría de las culturas políticas se identifica como "maldad", "subversión", o el "enemigo".

Sobre la base de este razonamiento, sugeriré, siguiendo a Tom Popkewitz, que identidad y diferencia, tanto como inclusión y exclusión, no son conceptos opuestos sino mutuamente imbricados, y que pueden ser tratados como un concepto singular que funciona como un doblez, habilitando y desalentando prácticas. La diferencia, o la exclusión, no sólo existen dentro de las identidades que incluyen, como este "afuera" constitutivo contra el que se recortan, sino que de hecho se producen en la misma operación. Aún los discursos más inclusivos califican y descalifican a la gente para participar (Popkewitz, 199 |, p. I 25ss.) y aún las identidades más inclusivas, como la nación o la democracia, pueden ser altamente excluyentes, como lo han probado en el pasado. Por otro lado, estos son procesos historicos y contingentes: la identidad en la que queremos incluir no es el producto de una "voz interior" que es innata en los seres humanos, o de una "evolución natural" de las cosas, sino el resultado de complejas dinámicas que involucran biografías personales y sociales afectadas por luchas y conflictos, y cuyo resultado nunca puede darse por sentado. Por lo tanto, la fijación de la diferencia como negativa o amenazante, su congelamiento como pura enemistad o maldad, es una decisión ética y política, y en tanto política, histórica, y por lo tanto abierta a cuestionamiento y cambio.

En el caso de los principios educativos modernos, la equivalencia entre igualdad y homogeneización produjo como resultado el congelamiento de las diferencias como amenaza o como deficiencia. Lo mismo y lo otro dejaron de ser conceptos móviles y contingentes para aparecer como propiedades ontológicas de los grupos o seres humanos, incuestionables e inamovibles. Si nuestra identidad es que seamos todos iguales, y ella se define no sólo por la abstracción legal de nivelarnos y equipararnos a todos los ciudadanos sino también porque todos nos conduzcamos 
de la misma manera, hablemos el mismo lenguaje, tengamos los mismos héroes y aprendamos las mismas cosas, entonces quien o quienes persistan en afirmar su diversidad serán percibidos como un peligro para esta identidad colectiva, o como sujetos inferiores que aún no han alcanzado nuestro grado de civilización. Creemos que este es el patrón básico con el que se procesó las diferencias en nuestras escuelas. Aparecieron una variedad de jerarquías, clasificaciones y descalificaciones de los sujetos, cristalizando la diferencia como inferioridad, discapacidad o incapacidad, ignorancia, incorregibilidad. En las secciones siguientes, analizaré con mayor detalle cómo esta construcción discursiva se desarrolló en Latinoamérica y especialmente en el sistema educativo argentino.

\section{MODERNIDAD LATINOAMERICANA Y RELOCALIZACIÓN DE LA INCLUSIÓN Y LA EXCLUSIÓN}

Las identidades en las cuales nos incluímos, o de las que somos excluídos, no suceden en un vacío; por el contrario, son producto de la historia y de localizaciones particulares. Autores contemporáneos definen a la identidad como ficciones narrativas que nos dan un sentido de permanencia en el tiempo y de pertenencia a grupos determinados, que se construyen a través de la historia. Por ejemplo, Stuart Hall, uno de los referentes más importantes de los estudios culturales, recuerda autobiográficamente que después de mudarse de Jamaica a Inglaterra, aprendió a ser un "inmigrante" y, lo que es todavía más importante, "descubrió" que era "negro". Este descubrimiento no implicó encontrar tampoco un lugar "tranquilizador". La negritud, escribe Hall,

....siempre ha sido una identidad inestable, psíquica, cultural y políticamente. También tiene una narrativa, un relato, una historia. Es algo construído, relatado, hablado, no algo que uno simplemente "encuentra". La gente habla ahora de la sociedad de la que provengo en formas que para mí no son reconocibles. Por supuesto que Jamaica es una sociedad negra, dicen. En realidad, es una sociedad de gente mestiza y negra que ha vivido por trescientos o cuatrocientos anos sin jamás haber sido capaz de hablar de sí misma como "negra". La negritud es una identidad que tuvo que ser aprendida, y que sólo pudo ser aprendida en cierto momento determinado. En Jamaica ese momento son los años '70. (Hall, 1996, p. I 16)

Lo que resulta ilustrativo de este relato de Hall es hasta qué punto las identidades implican una "puesta en escena" de la experiencia, una determinada 
organización y articulación de la experiencia, y que son vividas a través de discursos de saber que nos ayudan a darle sentido a quiénes somos, quiénes no somos, y en qué podemos convertirnos (Britzman, 1992).

La modernidad como proceso cultural, economico y político tuvo efectos importantísimos en términos de la constitución de identidades, y también de diferencias. Podría decirse, siguiendo la caracterización de Weber de las ciudades modernas, que la modernidad involucra la coexistencia de un homo economicus capitalista y de una esfera política y administrativa basada en la interacción de los ciudadanos. El mercado capitalista supone la emergencia de sujetos económicos que se basan en una ficción de equivalencia: en abstracto, todos somos individuos libres que intercambiamos nuestros bienes en forma equivalente. Esto fue posible, dice el urbanista Adrian Gorelik, porque se destruyó el

...carácter cerrado, integrado, de la sociedad tradicional...; la moderna "sociedad civil", de "integración incompleta", genera los dos atributos principales para la emergencia del espacio público: la equidad y la distancia, de la que surge la representación formalizada: formas sociales, formas urbanas, formas edilicias, formas de presentación pública (modales, vestimenta), formas políticas. Formas que permiten una esfera pública capaz de poner "entre paréntesis", por usar la figura de Habermas, las diferencias sociales. (Gorelik, 1998, p.39-40)

La identidad como individuos libres de un mercado común y de una sociedad nacional organizada más o menos democráticamente supone entonces que se suspendan las diferencias temporariamente en pos de una acción equivalente de todos los ciudadanos, y también que se articulen en forma nueva estas diferencias que aparecen como suspendidas. Los escritos de Tocqueville (Garcia Candini, 1990) sobre su viaje a America del Norte son una buena ejemplificación de este proceso. En "La Democracia en América", Tocqueville se sorprende ante el carácter plebeyo e igualitario de la sociedad de Nueva Inglaterra pero también alerta sobre la aparición de nuevas diferencias, más sutiles si se quiere, en las maneras de comportamiento, en los vestuarios, en toda la gama de distinciones que emergieron para dar cuenta de una nueva jerarquía social.

Si la esfera pública moderna puede definirse, entonces, como la elevación de la igualdad a principio/ficción fundante, y de la articulación de distancias o diferencias que organizan esta igualdad en un espacio social e histórico, cabe preguntarse cómo se produjo este proceso en una región geopolítica en la que la "puesta entre 
paréntesis" de las diferencias era cotidianamente desafiada por instituciones que la realzaban. Muchos analistas han tendido a ver esta "traducción de la modernidad" como un "eco diferido y deficiente de la modernidad de los países centrales" (Garcia Canclini, 1990, p.69, criticando esa postura). Incluso, en los debates sobre la posmodernidad latinoamericana, se ha argumentado que no se puede hablar de posmodernidad cuando la modernidad ha sido un proceso inconcluso e inacabado en América Latina. En ambos señalamientos, puede identificarse una misma visión de América Latina como un espacio secundario, periférico a la modernidad europea, que se limita a imitar, mal y a los ponchazos, las fortalezas del original.

Sin embargo, desde su propia estructuración, América Latina no fue un espacio geográfico vacío que se llenó con acciones y reacciones frente a la empresa colonizadora moderna, sino un producto de ella, parte y parcela de ese proceso. La propia definición de América, fruto de un cartógrafo alemán que quería rendir homenaje a Americo Vespucci en la identificación de un nuevo territorio descubierto por navegantes a las órdenes de la corona española, y aún de América Latina, erigida en el siglo $X I X$ y $X X$ en el símbolo unificador de la parte del continente heredera de los imperios español y portugués frente al avance del expansionismo norteamericano, fueron prácticas inscriptas en el corazón de la modernidad, de su voluntad de poder y de sus sueños civilizatorios. Representan, como dice Walter Mignolo, el "lado oscuro del renacimiento" y de la modernidad: el ámbito en que el saber y la cultura asumen claramente sus compromisos con el poder y la sujeción del otro (Mignolo, 1995). La originalidad de América Latina se encuentra en su localización en el borde del sistema colonial, en su interacción con culturas preexistentes, y en su estructuración particular de los sueños modernos, que constantemente debían recordar o confrontar su lado oscuro (Mignolo, 2000).

Este lado oscuro está presente por ejemplo en uno de los primeros actos pedagógicos ejecutados por los conquistadores españoles en tierra americana, el "Requerimiento o Conminación a los indios" escrito en 1513 por el jurista Palacios Rubio, que estuvo en vigencia hasta 1542 (Puiggrós, 1996). Este documento, redactado en respuesta a una disputa sobre la legitimidad de la guerra contra los indios, establecía que el Papa como representante de Dios en la tierra les había otorgado el continente americano a los españoles y portugueses. El texto

...suponía que los indios no habían sido informados de tal hecho, lo cual se reparaba en ese acto, leyendo el Requerimiento en presencia de un oficial del rey, pero sin intérprete. Los indios que se dieran por enterados y aceptaran la situación tras la 
lectura, se liberarían de ser esclavizados, pero a quienes no lo hicieran se les prometían tremendas penas para ellos y sus familias, además de la esclavitud. (Puiggrós, 1996, p. 16)

Para esta autora, se establecía que la relación pedagógica entre españoles e indígenas sería de dominación, y que la condición para conservar algunos derechos elementales era aceptar absolutamente y sin condiciones la cultura, la lengua, y la razón dominantes. Es decir, se procedía a una inclusión selectiva, basada en una aculturación brutal, y a la exclusión sistemática de otra parte de la población.

La exclusión lisa y llana de parte de la población siguió estando presente en los siglos siguientes, pero otros ideales identitarios fueron abriéndose paso en tanto el dominio colonial fue abolido, y se instauró en su lugar otro tipo de sistemamundo, neo o post-colonial. Sin embargo, el "lado oscuro" de la modernidad siguió teniendo una alta visibilidad. Puede encontrarse un ejemplo de ello en el liberalismo latinoamericano en el siglo XIX, que tenía que "negociar" con el racismo y el esclavismo permanentemente, evidencia de lo cual es la inclusión de la "Declaración de los derechos del hombre" francesa en la constitución brasileña de 1824 , mientras todavía estaba vigente el sistema esclavista. Esto ha sido senalado por un académico brasileño, Roberto Schwarz, quien propone que, dadas estas condiciones, el liberalismo latinoamericano era una "idea fuera de lugar" ', que combinaba la adopción de formalidades de la filosofía social liberal con la defensa del sistema oligárquico². La propiedad oligárquica, el fraude político y la desorganización eran algunas de las características de las sociedades latinoamericanas que planteaban estar organizadas y gobernadas sobre bases liberales. Schwarz argumenta convincentemente que la relocalización del liberalismo en tierras latinoamericanas puso a los liberales en el brete de reconocer que las ideas liberales eran tan impracticables como imposibles de rechazar. El progreso era una desgracia, experimentada en los procesos de modernización salvaje, pero frente a esta desgracia tampoco podía defenderse el atraso: ésta fue una de las paradojas constitutivas de nuestras sociedades.

I Cabe señalar que la posición de Schwarz ha sido polémica en el Brasil. Sus críticos han argumentado que la referencia a "ideas fuera de lugar" tiene un sustrato esencialista - como si las ideas tuvieran un lugar correcto y otro incorrecto. Por nuestra parte, nos acercamos a la obra de Schwarz a partir de la lectura que recupera García Canclini (1990), que enfatiza la multitemporalidad e hibridaciones que configuran las culturas latinoamericanas en la modernidad.

2 Para la definición de Estado oligárquico, consultar Cavarozzi, 1978. 
Este liberalismo sui generis se convirtió en la racionalización por parte de las élites del sistema de dominación política, justificando la exclusión de los acervos políticos y culturales de las grandes mayorías de la población. Al mismo tiempo, también produjo "ficciones de equivalencia" que planteaban la suspensión de las diferencias y la configuración de nuevas identidades inclusivas. La educación jugó un papel fundamental en esta uniformización igualizante y en la articulación de otras diferencias. En el apartado siguiente, nos ocuparemos en particular de la constitución del sistema educativo en la Argentina y de cómo se configuraron patrones de inclusión exclusión que todavía subsisten.

\section{SISTEMA EDUCATIVO NACIONAL EN ARGENTINA: DINÁMICAS DE INCLUSIÓN Y EXCLUSIÓN}

Como el lector probablemente sepa, la Argentina fue un asentamiento colonial marginal en el imperio español, y alcanzó su independencia en 1810. El estado nacional se construyó durante la segunda mitad del siglo XIX, mientras se cometía el genocidio de las tribus nómades del sur y el nordeste del país. Las élites locales de los estados provinciales debieron someterse al poder de una oligarquía centralizada, y las identidades provinciales y regionales, que hasta ese momento habían sido las formas de identificación colectivas primarias, fueron reprimidas y luego abandonadas (Chiaramonte, 1989). En esta misma época, la Argentina se convirtió en una tierra de inmigración. Desde I 860 a 1930, 6 millones de inmigrantes llegaron a la Argentina, la gran mayoría europeos pero también del Medio Oriente, que aportaron el 75\% del crecimiento de población total en el país. La gran mayoría se asentó en Buenos Aires, la ciudad capital, donde hacia 19 | 4 casi el 80\% de la población era inmigrante o hijo de inmigrantes (Sarlo, 1993). Aún en 1936, los extranjeros constituían el 36. $1 \%$ de la población de las grandes ciudades del Litoral argentino.

Un factor clave para integrar a esta población heterogénea fue la organización del sistema educativo nacional. La "ciudadanía letrada" (Sábato, 1992) educada por las escuelas sería el pilar del orden republicano oligárquico y de la unión nacional imaginada por los padres fundadores de la nación, la mayoría de ellos suscriptores de un liberalismo sui generis al que ya nos hemos referido. La instrucción pública fue concebida como la mejor garantía de que el pueblo soberano ejerza sus derechos de la manera correcta. Decía Sarmiento, uno de los líderes de esta generación: "Un pueblo iletrado siempre votará por Rosas" (caudillo porteño de la primera mitad del siglo XIX). La escuela era la mejor defensa contra los localismos y los caudillismos. 
Nos detendremos por unos instantes en la obra de Domingo Faustino Sarmiento ( 181 | - | 888), porque a nuestro entender su forma de articular la relación entre escuela y sociedad fue fundamental en la organización del sistema educativo nacional argentino. En su libro Facundo: civilización y barbarie( I 845), Sarmiento buscó entender "el origen del drama argentino", como él llamó a las luchas civiles que siguieron a la independencia de España y que obstacularizaron la formación de una nación unificada por casi 60 años. La explicación que dio fue cultural: la "barbarie" era el escollo para construir la nación. Para remediarla, Sarmiento indicó una serie de acciones que iban desde la represión y el exterminio ("Hay que regar la Pampa con sangre de gaucho", diría años mas tarde) hasta la escolarización masiva, incluyendo a las mujeres. Sarmiento creía que la construcción de la nación sólo sería perdurable si se lograban producir nuevos sujetos "civilizados" por medio de la educación. Su postura puede ser caracterizada como una generosa - y en muchos aspectos democrática - propuesta educacional que suponía sin embargo como condición previa la eliminación de todos aquéllos que caían en la descripción de "barbarie". La educación moderna que conduciría a una organización social más democratica y productiva sólo era posible a costa de reprimir o exterminar a parte de la población (apud Puiggrós, 1990). Esta postura fue fundante del optimismo pedagógico argentino, y generó la convicción de que, para pensar cambios o reformas estructurales, debía promoverse la escolarización masiva de una población sobre la que pesaba, casi como una daga, una fuerte desconfianza (Caruso, Dussel, 1996). Esto puede verse en la organización, algo posterior pero llevada a cabo por el mismo Sarmiento, de los Consejos Escolares en la provincia de Buenos Aires, que trataron de imitar a los Board of Education norteamericanos en su fase de participación y dinamismo social e invitaron a la población a incluirse en el gobierno educativo. A los pocos años, descontento con sus resultados, terminó aprobando su supresión o marginalización. Pareciera que los límites de la participación estaban dados de antemano, y que no había lugar para otro tipo de sujetos y acciones sociales que no fueran las prescriptas por el nuevo estado.

Desde 1870, en la Argentina tuvo lugar la construcción, desarrollo y diversificación de un sistema educativo nacional. La ley 1420 de educación obligatoria, gratuita y "laica" (o de religiosidad restringida mas bien), que se decretó en I 884, fue su base legal. En ella y en la legislación subsiguiente se hizo evidente la filosofía educativa de esta élite oligárquica: todos debían ser socializados de la misma forma, sin importar sus orígenes nacionales, la clase social o la religión, y esta forma de escolaridad fue considerada un terreno "neutro", "universal", que abrazaría por igual a todos los habitantes. 
Asi concebido, el sistema escolar público se convirtió en una máquina formidable de asimilación de la población provincial e inmigrante. La extensión de la escuela primaria y la introducción de una formación docente centralizada fueron los medios por los cuales estas masas heterogéneas se integraron a la sociedad argentina (Tedesco, 1986). Las tasas de alfabetización pronto alcanzaron los niveles de los países europeos occidentales: por ejemplo, en 1930, 95\% de la población de Buenos Aires estaba alfabetizada, y 30\% de la población etaria iba a la escuela secundaria (Tedesco, 1986)3. Surgió así un amplio público lector que consumía libros, revistas y diarios, y que combinaba saberes de distinta procedencia. La literatura de masas que tuvo su auge en esa época a través de las novelas semanales y de ediciones adosadas a los periódicos tenía muchos puntos en contacto con la cultura "alta", y era usual encontrar a Borges y Bergson en los magazines que se vendían masivamente en las décadas de 1920 y 1930 (Romero, Gutierrez, 1992). Argentina, y sobre todo Buenos Aires con sus altos indices de escolarización y su diseño urbano modelado por arquitectos parisinos y españoles, se veía a sí misma como la nación líder de Latinoamérica y como la más europea y europeizante. En los mitos colectivos que forjaron el imaginario nacional, la Argentina se presentaba como un crisol de razas en el que todos eran bienvenidos y podían progresar en la sociedad y en la cultura.

Sin embargo, como se argumentó anteriormente, las formas de inclusión social conllevan también exclusiones. La identidad nacional común requería, tal como el pacto republicano, el abandono de identidades particularistas y también de filosofías individualistas liberales, vistas como una fuente de anarquía por la mayoría de los organizadores del sistema escolar. Para convertirse en sujetos nacionales, los inmigrantes debían abandonar su lengua, sus costumbres, sus héroes y sus formas de vestirse y relacionarse. El sistema escolar participó activamente en esta campaña, que recibió el pomposo título de "Cruzada patriótica", vigilando de cerca que se practicaran y respetaran el español correcto, las memorias correctas, y las reglas sociales correctas. Un ejemplo de esta cruzada puede encontrarse en libros de texto del período, que enfatizaban la necesidad de renunciar a los héroes y símbolos identitarios de otras naciones de origen y "abrazar" la narrativa nacionalista sobre la Argentina (Braslavsky, 1993).

3 Los datos para España en la misma época señalan que el 32\% de la población era analfabeta, y que en Madrid el porcentaje de analfabetos sobre la población total era del $14 \%$ y en Cataluña del $21 \%$ (Vilanova Rubias, Moreno Julià, 1990, p. 378). 
A través de la adopción de una pedagogía medicalizada, los niños fueron "normalizados" y sujetos a reglas disciplinarias y rituales estrictos (Puiggrós, 1990). Las prácticas docentes debían seguir métodos científicos que podrían ser replicados a traves del país. Junto con ellos, surgió una serie de reglas e instrumentos clasificadores de la población escolar. En el apartado siguiente analizaré con mayor profundidad algunas de las características de esta pedagogía "normalizadora", que estructuraron las bases de la inclusión de muchas generaciones de niños y también de una persistente exclusión.

\section{La pedagogía normalizadora: clasificación y regulación de alumnos y maestros $^{4}$}

Adriana Puiggrós ha denominado "normalizadores" a una serie de pedagogos laicos y católicos argentinos que hacia fines del siglo pasado impusieron un modelo de enseñanza-aprendizaje que tendría vastas repercusiones hasta nuestros días (Puiggrós, 1990, p. 4lss). Tomando la noción de normalización de Michel Foucault, la autora argumenta que esta pedagogía se basó en la creación de una norma o cuadrícula general en términos de la cual se puede medir cada uno de los individuos, e identificar si cada uno cumple con ella o se desvía del parámetro común. Así, la norma supone la idea de que hay que "corregir" al individuo desviado, ya sea vía el castigo o vía la adopción de estrategias de refuerzo que eviten que la conducta transgresora vuelva a repetirse. La pedagogía se convierte en algo normativo: prescribe cuál es la conducta "natural" y esperable, y por lo tanto "genera" y "produce" lo anormal, la transgresión, la desviación. "La norma es una medida, una manera de producir la medida común" (Ewald, 1990, p. 168). En ese acto de producir la vara común, la instauración de la norma excluye a quienes no la cumplen. No es casual que sea en esta época que aparece la clasificación de los alumnos según sus capacidades, y que se confine a los "anormales" en instituciones especiales. Nótese el lenguaje que se utiliza para referirse a los "desviados": "deficientes", "anormales", "dis-capacitados". Todos estos calificativos sólo adquieren sentido cuando se los compara con un individuo "normal".

Puede observarse, como ejemplo de esta voluntad normalizadora, la proliferación de clasificaciones y jerarquizaciones de los alumnos según sus caracte-

4 Este apartado sintetiza y reelabora algunos planteos realizados en el capítulo 4 de La invención del aula: una genealogía de las formas de enseñar (Dussel, Caruso, 2000). 
rísticas y rendimiento escolar, que se hizo muy popular a principios del siglo $X X$ en toda América y por supuesto también en Europa. Stephen Jay Gould (|98|), en su libro La medida del hombre, proporciona una descripción y crítica exhaustiva a estos modelos de clasificación de la inteligencia, estrechamente vinculados a las estructuras clasistas, racistas y sexistas de las sociedades. Esta tendencia puede ilustrarse en el artículo que publicó, en 1910, en la revista del Consejo Nacional de Educación de la Argentina, la doctora Hermosina de Olivera, en el que decía que había niños "atrasados", y que éstos debían clasificarse como sigue:

a) la muchedumbre heterogénea que por su organización psíquica y física es incapaz de aprovechar los métodos comunes de enseñanza;

b) los imbéciles, idiotas, sordomudos, ciegos y epilépticos;

c) los distraídos, como prefieren llamarlos los padres, o atrasados. No son simplemente anormales y están atacados de debilidad mental por causas múltiples y pasajeras. Son especialmente los hijos de nuestra masa obrera, con funcionamiento lánguido del cerebro, producto de una alimentación deficiente. Perturban la disciplina, ocupan inútilmente un lugar en las clases comunes, desalientan a la maestra e influyen en sus condiscípulos. (Apud Puiggrós, 1990, p.|34-135)

Lo importante para los científicos de esa época era analizar las sociedades como producto de regularidades y normas; encontrar las leyes que las gobernaban, y explicar por qué a veces las cosas se desviaban de ese camino prefijado que es el crecimiento. Los imbéciles, los idiotas, los distraídos o desatentos, debían ser estudiados y confinados en su lugar en la grilla, para analizar si correspondían acciones remediales o los casos eran, valga la redundancia, sin remedio.

Los pedagogos "normalizadores" fueron quienes construyeron los pilares del sistema educativo argentino a fines del siglo pasado y principios de éste. El nombre de "normalizadores" también se vincula al hecho de que muchos de ellos fueron egresados de las primeras escuelas normales que se fundaron en el país, notablemente de la Escuela Normal de Paraná y de las Escuelas Normales N. I y 2 de la Capital Federal. A través de ellas, se difundió una pedagogía que reformó las formas de enseñar y aprender en la Argentina (Pineau, 1997). Fruto de su actividad profusa, incesante, minuciosa, son los planes de estudio, códigos disciplinarios, edificios escolares, textos pedagógicos, que formarían a buena parte de los maestros de este siglo. Aún cuando hubo disidencias muy importan- 
tes ${ }^{5}$, fueron los normalizadores quienes impusieron su concepción del vínculo pedagógico y estructuraron las bases de una relación entre maestros y alumnos en el aula por largos años.

Nos interesa especialmente detenernos en cómo concibieron ellos la estructura del aula, enmarcada en lo que fue llamado "la táctica escolar". Esta expresión era usada desde 1880 en las escuelas argentinas. En un artículo publicado en I 884 y titulado "La táctica escolar", un colaborador anónimo de la Revista de Educación (editada por la Dirección General de Escuelas de la provincia de Buenos Aires) decía que: "los movimientos que maestros y alumnos necesitan ejecutar en la escuela, tienen mucha semejanza con los movimientos militares, y como éstos deben tener aquéllos una táctica especial" (apud Pineau, 1997, p.95). También constituía una bolilla del programa de pedagogía de primer año de las escuelas normales en 1903, y apareció en el libro de pedagogía de Senet para las escuelas normales de 1918 como capítulo especial.

Tal como lo habían hecho los pedagogos lancasterianos casi un siglo antes, la metáfora militar era usada una vez más para pensar lo que sucedía en las aulas. La idea de que había que ordenar al conjunto, establecer un sistema de jerarquías, volver dóciles a los cuerpos, seguía teniendo vigencia. La táctica escolar, definida por Senet como "un sistema de señas y movimientos" (Senet, | 9| 8, p. I I 5), ayudaba a lograr el orden, ahorraba tiempo, y creaba en los alumnos el hábito de la obediencia y traía la uniformidad en los movimientos. Dentro de esta táctica, Senet se dedicó a normar aspectos de la vida escolar que hasta entonces eran más laxos y flexibles: horario de entrada y salida de la escuela, toque de campana antes de iniciar las clases, formación de filas al entrar al aula, respeto de los recreos, formas de salir de la escuela sin aglomeraciones; hasta le preocupó escribir párrafos sobre la necesidad de que los alumnos se queden de pie al lado del asiento hasta que el profesor les ordene sentarse.

Senet planteó que los alumnos debían ejecutar movimientos uniforme y simultáneamente, y que el maestro debía estar siempre en control de la situación. El maestro debía pautar cuáles eran las formas y tiempos de levantarse y sentarse, sacar y guardar los útiles, salir del aula. Seguía siendo el "sol" que Comenio imaginó en las primeras formulaciones del método global; todo debía organizarse en torno a él, como rayos que irradiaban sobre cada uno de los alumnos-planetas. Por ejemplo,

5 Para ellas, referimos al citado libro de Puiggrós (1990), especialmente a la parte 2, en que se ocupa del pedagogo Carlos Vergara. 
Senet decía: "Se evitará, ante todo, que los alumnos conversen en clase. Las conversaciones se hacen entre profesor y alumnos; el cuchicheo de los últimos impide la enseñanza y distrae la atención de todos" (Senet, 1918, p. 123). Nada de aprendizaje colaborativo, ni entre pares: la táctica escolar se organizaba como un intercambio radial entre el centro docente y los niños aislados.

Siguiendo a la filosofía positivista, muchos de los pedagogos normalizadores consideraron que todo podía englobarse bajo leyes generales, las que debían respetarse casi como a una ley sagrada. Las leyes no sólo alcanzaban al aprendizaje y la conducta de los alumnos, sino que, sobre todo, planteaban reglas y principios rígidos para el accionar docente. El incremento de la regulación del trabajo docente trajo una mayor exigencia, porque todos debían ajustarse por igual a las reglas naturales, expresadas en los reglamentos escolares formulados "científicamente". Debe tenerse en cuenta que en aquel entonces, debido a la escasez de maestros egresados de las escuelas normales, solo una porción minoritaria eran "titulados" oficialmente (esto es, egresados de instituciones reconocidas), y buena parte eran personas con intereses diversos por enseñar, cuya "idoneidad" y autonomía era motivo de preocupación creciente. Para evitar desvíos, y para promover una mayor homogeneidad en la enseñanza, se incrementaron los requisitos para la titulación: mientras que antes los educadores podían obtener un certificado de competencia de las autoridades escolares, esto crecientemente se fue dificultando, y se establecieron complejos exámenes para aquellos que no concurrieran a las escuelas normales o profesorados pero quisieran ejercer la docencia (Pineau, 1997).

La imagen del docente que se fue conformando a través de esta regulación creciente fue la de una personalidad sin fisuras, representante del Estado o la República, encargado de una misión superior a la que debía abocar todas sus fuerzas. Recomendaba Senet: "El profesor tendrá buen cuidado de que toda orden que dé sea cumplida; así es que antes de ordenar, debe pensarlo, y si duda de que su orden será estrictamente cumplida, es lo más conveniente que se abstenga de darla" (Senet, 1918, p. 129). La autoridad que emergía de estas recomendaciones era absoluta, perfecta, indiscutible porque era "científica". En un artículo del inspector Félix María Calvo, estas prescripciones adquieren ribetes casi inhumanos:

El maestro debe seguir paso a paso las evoluciones de la inteligencia infantil para sujetar la marcha de la enseñanza a un orden metódico y gradual: un paso en falso, un salto impremeditado, una exigencia inmoderada, trastornan el espiritu, como se 
trastorna la marcha de un reloj cuando se altera el engranaje de las cuerdas o se le da más cuerda de la necesaria. Un buen maestro, un verdadero pedagogo, no se equivoca en la aplicación de los principios y leyes que rigen el desarrollo físico y el intelectual, ni en el modo de infundir sentimientos nobles que han de formar el carácter del niño. (1900, p.67)

Para este inspector, el educador conduce de la mano al niño en una marcha que está sujeta a leyes fijas, y "cualquier infracción de esas leyes puede ser en extremo perjudicial”. Este perjuicio era rápidamente traducido en términos médicos:

...cualquier descuido de parte (del maestro), engendra un mal hábito ...con detrimento de la salud del educando... Y una cuestión tan sencilla como la mala posición del cuerpo trae consigo, en más de un caso, los desastrosos efectos de una tisis prematura o de una aneurisma. $Y$ esto no es exagerar los peligros: me atengo a la opinión de los hombres de ciencia, de autoridad indiscutible. (Calvo, 1900, p. 69)

En esta época, aparece con fuerza la idea de los "niños débiles", niños de complexión física y emocional frágil que deben ser tratados en forma especial. Se diseñaron sistemas de salud escolar que detectaran las patologías asociadas a la "debilidad", y algunas acciones de refuerzo, como las colonias de recuperación de la salud, las visitas médicas domiciliarias, y formas de educación especial. Nótese que la idea de "niño débil" está marcada por el vocabulario darwiniano de la fuerza vital y la sobrevivencia del más apto. Estos niños débiles deben ser objeto de detección temprana para no entorpecer el desarrollo de los fuertes y para recibir alguna educación compensatoria.

En términos generales, puede decirse que la pedagogía tomó como modelo a la biología, y ésta rápidamente se medicalizó: quienes se desviaran de la norma formarían a sujetos deficientes, anormales, enfermos. Y si los reglamentos se confeccionaron siguiendo estas leyes científicas, el incumplimiento de la normativa traería graves consecuencias. De ahí que apareciera un reglamentarismo a ultranza entre los inspectores y directivos de la época (Dussel, 1996).

La asimilación de la pedagogía a la biología también trajo como consecuencia el determinismo en la consideración de quiénes podían triunfar en la escuela y quiénes iban a fracasar. Decía el pedagogo argentino Víctor Mercante, quien fuera uno de los primeros egresados de la escuela normal de Paraná, maestro, director de escuela, inspector, profesor de la Facultad de Ciencias de la Educación de la Universidad de La Plata, y creador del Laboratorio de Paidología de dicha universidad: 
La herencia es de una fuerza transmisora tan potente que los pedagogos se han visto en la necesidad de seguirla, proclamando, por una parte, la concurrencia, por otra la sublimación del instinto, por otra la educación vocacional, espontánea y oportunista, en oposición a las disciplinas antinómicas del sentimiento y la obligación contrarias a la tendencia. La educación adapta lo que ya está adaptado. Cifra sus éxitos sobre el camino trazado por los padres y abuelos. Desde que el individuo trae a sus malas inclinaciones, sumadas muchas buenas, el problema escolar consiste en cultivar éstas y no ejercitar aquéllas. (Mercante, 1927, p. 46)

Mercante ideó, a partir de estas concepciones sobre la herencia y la raza, una serie de instrumentos para recabar información sobre los niños y sus familias que ayudarían a predecir sus resultados escolares y sus futuros comportamientos sociales. Por ejemplo, propuso que la escuela realizara una "anamnesis de familia", esto es, un trabajo de investigación sobre los orígenes del niño, indagando los datos sobre abuelos, padres y hermanos referidos a: raza, edad, origen, enfermedades, conductas, aptitudes profesionales, bienestar económico, régimen de vida doméstico y público, relaciones sociales, alimentación, frecuencia escolar, aplicación y aspiraciones. Estos datos deberían recogerse a través de "conversaciones afables" con la familia, tales como lo hacen los psiquiatras, y de visitas a sus hogares; y volcarse en una ficha que podría suministrarse a quien la requiriera, y que tendría tanto valor como "un acta de nacimiento" porque permitiría explicar y predecir las conductas (Mercante, 1927, p.48). En la imaginación de Mercante, la escuela debía sumarse a otros dispositivos de vigilancia y de control de la población, y producir información tanto o más fidedigna que los archivos policiales (Dussel, 1996a).

Puede verse a partir del desarrollo de la pedagogía normalizadora cómo se va definiendo una escolarización que parte de la educabilidad de gran parte de la populación y que al mismo tiempo opera una serie de jerarquizaciones y clasificaciones que congelan y cristalizan relaciones sociales más generales, y que postulan un vínculo autoritario entre las generaciones y también entre el estado y el pueblo. El docente, representante del estado, ejecuta y practica una serie de discriminaciones entre sus alumnos, obligados a desempeñarse de acuerdo a normas rígidas de supuesta base científica y profundamente sospechados ante la menor desviación de "atavismos", "barbarie", "imbecilidad”. Dispone para ello de una pedagogía de bases supuestamente científicas que organizan a la población en torno a un paramétro ideal y ubican a cada individuo en una cuadrícula preestablecida. 
Pero a su vez el docente mismo es objeto de una regulación cada vez más exhaustiva, que le dice qué debe hacer en cada caso y que lo somete a penalidades y vigilancias crecientes. Cabría preguntarse cuánto de esto aún está presente en las reformas contemporáneas, que adoptan otros parámetros (constructivismo, creatividad, participacionismo) pero siguen estableciendo normas y prescripciones que producen nuevas exclusiones. Sobre ello volveremos en los comentarios finales.

Si hasta ahora la pedagogía normalizadora puede parecer como opresiva y compacta, sin matices, cabe destacar que logró ser eficaz precisamente porque pudo articular la voluntad de inclusión social con prácticas diferenciadoras y autoritarias. Permítasenos dar un ejemplo de este imaginario que combinaba homogeneidad y autoritarismo con proclamas progresistas de igualdad y progreso social a través de la historia de una maestra, registrada por una crítica cultural argentina, Beatriz Sarlo. Esta maestra, hija de inmigrantes españoles, logró ingresar a la escuela normal con mucho esfuerzo personal y familiar (su padre era obrero textil y su madre cosía para afuera desde su casa). Una vez egresada, se convirtió en directora de una escuela situada en un barrio pobre de la capital a principios de 1920, donde la mayoría de sus alumnos eran inmigrantes de primera o segunda generación de Europa del Este, muchos judíos, y en cuyos hogares no se hablaba español. En su primer día de clases como directora, formó en filas a sus pequeños alumnos, y separó a varios varones, a quienes dejó parados en el patio de la escuela mientras llamaba al barbero. Este vino y procedió a rasurar las cabezas de los alumnos en el mismo patio, por orden de la maestra. Ella aún recuerda, 70 años después, que el patio escolar estaba cubierto por una masa de pelo finito, como si fuera, dice, la nieve que nunca había visto. En su relato, no considera la posibilidad de preguntar a los padres sobre la conveniencia de esta acción, ni preguntar o informar a los niños sobre lo que les iba a suceder. La maestra justifica su acción diciendo que, si se les dejaba el pelo, los niños hubieran propagado piojos a toda la escuela, y que lo primero que quería hacer en su día inaugural era dar una lección práctica a todos (Sarlo, 1997, p. 187).

Si bien el relato nos conmueve por su brutalidad, debe dejarse en claro que esta maestra cree que es perfectamente adecuado rasurar a sus alumnos en nombre de la salud y la cultura. Esta naturalidad nos da algunas pistas sobre el tipo de intervención operado por el sistema escolar moderno sobre los sujetos escolares en la Argentina. Cabe señalar que esta misma maestra ponía plata de su salario para pagar ropa para los niños y para comprar telas para que todos pudieran vestir 
escarapelas argentinas (distintivos patrios, hechos de retazos de la bandera nacional). Beatriz Sarlo titula su escrito sobre esta historia "Cabezas rapadas y cintas argentinas": ambos términos constituyen símbolos de la inclusión a prácticas sociales y escolares que conllevaban también sujeciones y exclusiones.

En el apartado siguiente, voy a analizar en detalle la historia de los delantales o guardapolvos blancos en las escuelas argentinas. Símbolos favoritos de la inclusión promovida por la escuela pública, al punto que los maestros argentinos los erigieron en distintivos de su lucha contra la reestructuración educativa en años recientes, los guardapolvos conllevan también la construcción de diferencias. Por ello, aparecen como un objeto privilegiado para estudiar la articulación entre la voluntad de inclusión y las prácticas diferenciadoras.

\section{Uniformidad y exclusión: el caso de los guardapolvos blancos}

Los guardapolvos o delantales blancos que se adoptaron en las primeras décadas del siglo XX en la Argentina, Uruguay y Bolivia fueron, como hemos dicho, uno de los puntales de la inclusión y homogeneización de la población escolar. Para evitar la diferenciación social por las apariencias y vestuarios, se estableció, primero en algunas escuelas y paulatinamente en todo el sistema educativo, que los niños debían ir a la escuela con un delantal blanco sobre sus ropas. Este uniforme, que se parece al que usan los médicos y enfermeras, tenía, además de fundamentos igualitarios y moralizantes, fines profilácticos, como prevenir la propagación de gérmenes y bacterias (Dussel, 2000). En el caso argentino, poco tiempo después de extenderse su uso entre los alumnos, se obligó a los maestros a vestir el mismo delantal. Se pensaba que el delantal cubría las diferencias y las borraba, instaurando una apariencia igualitaria a toda la población escolar. La igualdad era pensada como homogeneidad: si todos aparecían como equivalentes, no se podrían realizar distinciones y discriminaciones. Retomando las ideas desarrolladas anteriormente, puede señalarse que el guardapolvo era un símbolo privilegiado de esta suspensión de las diferencias y de la creación de una ficción de equivalencia entre todos los cuerpos.

La idea de uniformar a los niños proviene de las escuelas de caridad y lasallianas en los siglos XVII y XVIII, pero tuvo un espaldarazo definitivo en las propuestas de la Revolución Francesa, que intentó abolir las diferencias entre castas y sectores sociales igualando la vestimenta de niños y adultos (Dussel, 200 I). A finales del siglo XIX, sin embargo, Sarmiento y otros líderes educativos no suscribieron a esta práctica, con 
la convicción de que una vestimenta obligatoria excluiría antes que incluiría a muchos niños, y comportaría una erogación que muchas familias pobres no estaban en condiciones de realizar. Es de sospechar también que la oposición a la educación religiosa, del cual el uniforme estilo sotana era un símbolo, jugó un papel importante en el rechazo a la uniformización de los escolares.

A pesar de esta prohibición de exigir una vestimenta especial, que se hizo explícita en los reglamentos para la escuela primaria, la cuestión del vestuario adquirió relevancia como parte de las tareas "civilizadoras" y modernizadoras de la escuela. Puede ilustrarse esta preocupación con el relato de uno de los maestros norteamericanos traídos por Sarmiento para reorganizar el sistema de educación pública entre 1869 y 1898 . John Williams Stearns relataba en una carta a sus familiares escrita entre 1875 y 1877 que cuando organizó la escuela normal de Tucumán tuvo que cambiar las pautas de vestimenta de los alumnos.

Aquí los niños más pobres van completamente desnudos o apenas con una camisa andrajosa, y aún aquéllos de la clase media, sin lavarse ni peinarse, y vestidos con ropas que consideraríamos apropiados sólo para los mendigos... Hemos librado batalla, y con sólo rehusar la entrada a los que no concurran decentemente vestidos, se ha producido un cambio milagroso. La escuela tiene fama de estar muy por encima de cualquier otra de la ciudad, y antes que perder la oportunidad de enviar a sus hijos aquí, los padres han preferido comprarles ropas nuevas. (Apud Houston Luiggi, 1959, p. 104)

El cambio operado en el aspecto y modales de los alumnos era, para Stearns, uno de sus mayores motivos de orgullo.

Si el escenario que describían los maestros y maestras norteamericanas era uno donde primaba la desorganización y la heterogeneidad en el vestuario, hay que destacar que la introducción del guardapolvo en las primeras décadas de este siglo modificó el paisaje de las escuelas argentinas. Siguiendo el ejemplo de las escuelas francesas, se adoptó un uniforme que cubriera la ropa y que igualara a todos los alumnos pese a sus diferencias sociales. En el caso francés, se usaba un blusón negro, gris o azul, mientras que en la Argentina se adoptó un uniforme blanco. Dado que el guardapolvo era un elemento fácilmente accesible y relativamente barato, no habría más pobres excluidos de la escuela por vestimenta inapropiada, como en el caso de Stearns. Según este argumento, una vez educados por igual los ricos y los pobres, los naturalmente talentosos se destacarían por sí solos, y las 
diferencias sociales corresponderían a las diferencias "naturales" de inteligencia y capacidad ${ }^{6}$.

El uniforme operaba como símbolo de austeridad y de homogeneidad, que por otra parte se vincula a otras modificaciones en las presencias públicas de los cuerpos para aquélla época (Traversa, 1997). En oposición al modelo aristocrático que había sido predominante en el vestuario durante todo el siglo XIX, que privilegiaba el lujo, la ostentación y el exceso de ornamentación, el estilo republicano deshechó los colores vivos y se refugió en telas lisas y despojadas, o discretos rayados, denunciando al estilo anterior como inconveniente o indecente (Perrot, 1987). En esta jerarquía de lo ascético o austero, los niños estaban ubicados en el peldaño superior, y en las revistas de la época los niños "modelo" vestían trajes de marinero, capas navales, o uniformes escolares (Traversa, 1997; Paoletti, Kregloh, 1989).

Es importante destacar que la idea del delantal como código de vestuario dictaminado unilateralmente por la autoridad se vinculaba a la prevalencia de un régimen disciplinario bien descripto por Foucault ( 1977), y que nos recuerda sobre el lado oscuro de la modernidad. Mientras que en la era clásica el cuerpo de los condenados era propiedad del rey, y éste le imprimía su marca a hierro y fuego, con la emergencia de las disciplinas como régimen de saber/poder el cuerpo pasó a ser un bien social, "objeto de una apropiación colectiva y útil" (p. | |3). La persona que rompía las reglas o quebraba la ley era entonces considerada como enemiga o traidora. Como dice Foucault, es una "lucha desigual: de un solo lado, todas las fuerzas, todo el poder, los derechos todos" (p.94). Puede vincularse esta idea de la apropiación colectiva o social del cuerpo con los recuerdos de la pedagoga brasileña Guacira Lopes Louro sobre su experiencia con los uniformes escolares. En su escuela, las niñas eran consideradas responsables de "representar la escuela" a la sociedad toda. El uniforme conllevaba la obligación de portarse adecuada y respetuosamente, en cualquier lugar y en cualquier momento en que se lo vistiera, porque siempre se estaba representando al cuerpo social (Lopes Louro, 1998, p. 19). La construcción del cuerpo como propiedad colectiva, y de la transgresión como traición a la sociedad,

6 Lo que este argumento, que después se transformó en el de "igualdad de oportunidades", no toma en cuenta es que la "inteligencia" está conformada y mediada por procesos de interacción social, y se mide a través de valores y escalas que no son indiferentes a los conocimientos y actitudes que se aprendieron en las familias. Sintetizando un argumento complejo, diremos que esas diferencias de inteligencia no son "naturales" sino que son parte de los diferentes lugares en que las familias y grupos sociales de origen se posicionan en la producción y transmisión de la cultura (Bourdieu, 1988). 
ha permeado la manera en que los uniformes y guardapolvos fueron y son legislados en las escuelas.

El uso del delantal tenía además otras connotaciones que es importante destacar. El uniforme daba, y aún da, un sentido de pertenencia y de comunidad que ayudó a la expansión del sistema educativo en la Argentina. El orgullo de vestir el guardapolvo estaba asociado a que era un símbolo de inclusión en las dinámicas de movilidad social ascendente, que representa el dramaturgo Florencio Sánchez en "M'hijo el doctor" en la década de 1920, entre otros. También tenía la ventaja de instaurar parámetros claros sobre la obediencia a la autoridad (Joseph, 1986; Synott, Symes, 1995). El uniforme daba señales claras sobre quién transgredía las reglas, y volvía más fácil detectar a un alumno que se "hacía la rata" y andaba fuera del colegio en horas de clase, como proponía en su Didáctica el inspector Leopoldo Lugones en 1910 (Lugones, 1915).

Por otro lado, la difusión del guardapolvo blanco encuentra fundamento en el discurso médico que es característico de la pedagogía de esa época (Puiggrós, 1990). El delantal surgió paralelamente a la declaración de la "guerra contra los microbios” por Louis Pasteur y sus seguidores (Latour, 1988). Los médicos y científicos de laboratorio empezaron a usar delantales como forma de protección propia y de los pacientes frente a lo que empezaron a percibir como la "amenaza de los gérmenes". Inicialmente éstos eran oscuros, tanto por higiene como porque parte del personal hospitalario era miembro de órdenes religiosas y vestían hábitos, pero entre 1880 y 1920 el blanco pasó a ser dominante. Avisos de la época recomendaban a los médicos su uso para mostrar una imagen "limpia, prolija, fresca, científica" a la sociedad (Blumhagen, 1979, p. I 13). El blanco pasó a asumirse como símbolo de vida, salud, justicia, pureza. No es casual que se produjera esta asociación entre la blancura y la virtud en el marco del auge de las teorías de la supremacía de la raza blanca sobre las otras?

7 El trabajo de Martin Bernal, Black Athena ( 1987), aunque ha sido discutido historiográficamente, tiene el gran mérito de haber puesto de relieve que este proceso de "emblanquecimiento" de la historia occidental fue deliberado y central para la formación de la cultura occidental. Bernal se pregunta, por ejemplo: iporqué los griegos se presentan como blancos o arios en la historia que conocemos, cuando es altamente probable que fueran más bien mulatos o negros, dados los vínculos con el Asia Menor y con Africa? Para responderla, analiza los trabajos de historiadores, filósofos y pedagogos del siglo pasado, y demuestra que toda una parte de la historia fue borrada o excluida de los cánones oficiales para sustentar el argumento de la supremacía blanca. 
La adopción del guardapolvo blanco en las escuelas fue paulatina, y en ella jugó un rol central el estado nacional a partir del gobierno de Yrigoyen (19161922), primer gobierno electo por sufragio obligatorio y secreto. Un año antes de su asunción, se estableció que en las escuelas dependientes de la Nación estaba permitido el uso de uniformes o delantales; al mismo tiempo, se prescribió su uso para los docentes, quienes debían aparecer como modelos ejemplares de modestia y decoro. Durante el gobierno yrigoyenista, el estado nacional impulsó la creación de asociaciones cooperadoras por escuela, constituidas por padres o ciudadanos activamente interesados en la educación, que estarían a cargo de brindar guardapolvos a quienes no pudieran comprarlos por sí mismos. En las décadas de 1930 a 1950 , el estado asumió en forma directa la distribución de vestimenta, incluyendo delantales y calzados, a todo el país.

La implantación del uniforme, vivida según algunos testimonios orales como un acto igualitario y democrático, quiso borrar las diferencias sociales y la particularidad de los cuerpos. Sin embargo, las marcas sociales se abrían paso más tarde o más temprano en la ropa debajo del guardapolvo, los zapatos, los abrigos, y la disponibilidad de útiles escolares. Esto, por supuesto, no es privativo de la Argentina. Un educador inglés recuerda aún con pavor el día en que se le ensució su único saco azul (en Inglaterra, el uniforme de las escuelas públicas consistía en un saco azul y pantalón gris), y tuvo que concurrir con un saco gris, el único alumno frente a 600 alumnos uniformados de azul (Corrigan, 1988, p. 1 55). Obviamente, de tener más de un saco, tal episodio no hubiera ocurrido. Puede recordarse aquí que la ficción de equivalencia es precisamente eso, una ficción, que cotidianemente es objeto de cuestionamiento y de desafío por parte de las estructuras jerarquizadoras y discriminadoras de nuestras sociedades.

La presencia del guardapolvo también dio una nueva configuración a viejos conflictos generacionales. En torno a él, se articularon luchas de los adolescentes en desafío a la autoridad adulta (Gagliano, 1997). La altura de las polleras, o del escote, fueron motivo de rebeldías y síntoma de pequeñas transgresiones diarias, más o menos exitosas. Durante la última dictadura militar (1976-1983), que tuvo a la juventud como uno de sus blancos preferidos, el tema de los códigos de vestimenta en la escuela fue particularmente álgido. A partir de 1977, los alumnos no podían concurrir a las escuelas con jeans, ni con minifalda; se hicieron obligatorios el pelo corto en los varones y recogido en las mujeres, quienes tampoco podían usar maquillaje o aros notorios. Los límites de lo permitido se habían restringido considerablemente, y el guardapolvo o uniforme parecía haber sido desbordado por pequeñas muestras de rebeldía que debían ser castigadas. 
La reinstauración de los gobiernos constitucionales en 1983 trajo aparejada en la mayoría de los casos la relajación de las normas disciplinarias y de la vestimenta. En muchas escuelas secundarias se procedió a elaborar colectivamente códigos disciplinarios, donde generalmente figura en un lugar prioritario el tema de qué pueden y deben vestir los adolescentes. En algunos casos, se decidió el uso de distintivos o escudos para simbolizar la pertenencia a la escuela (Birgin et al, 1994). Por otra parte, en la mayoría de las escuelas primarias el uso del guardapolvo sigue siendo dominante, y en la legislación se señala que el delantal es el símbolo de la escolaridad pública y que seguirá siendo obligatorio. También parece serlo en algunas escuelas secundarias de sectores populares. Un testimonio recogido en un estudio etnográfico realizado el año pasado en un barrio marginal señala las causas de esta persistencia: "Yo me siento cómoda viniendo [a la escuela] en guardapolvo, porque eso quiere decir que sos una persona en progreso, quiere decir que sos una estudiante", relata la adolescente Laura, preocupada por diferenciarse de "los pibes de la esquina" que abandonaron el colegio. El guardapolvo diferencia y prestigia al mismo tiempo (Duschatzky, 1999, p.58). El hecho de que el guardapolvo blanco se haya convertido en el estandarte de lucha que los dirigentes del sindicato docente CTERA entregan en reconocimiento a algunos visitantes en el ayuno en la Carpa Blanca, y el que los maestros ayunantes lo vistan todo el tiempo, también habla de su poder simbólico como referente de una tradición de escolaridad pública común.

Sin duda, el delantal blanco, a través de la historia del sistema escolar y de la cultura argentina en el último siglo, ha venido a representar deseos y aspiraciones de inclusión y justicia social legítimos y laudables. En este sentido, es un emblema de una tradición igualitaria que sigue siendo necesario sostener, aunque en una forma renovada. Pensando en términos de la inclusión y la exclusión que produce la escuela, hay que alertar que los delantales portan otros significados ademas de la pretendida igualdad de los sujetos, que hacen a las formas de construcción de la autoridad escolar y docente, y a la intención de borrar y ocultar los cuerpos y las diferencias, lo que trae consecuencias en términos de los aprendizajes que se realizan en las escuelas y en términos de la cultura política y la vida democrática de nuestras sociedades. Lejos de lo que dice el refrán de "las apariencias engañan", sostenemos que las apariencias nos marcan y configuran tanto como una incisión quirúrgica, mucho más de lo que percibimos (Grosz, 1995).

En ese sentido, no se trata de prescribir si en la escuela debe o no usarse delantal, o aún si el delantal es una forma más inclusiva que excluyente, sino de pensar los sistemas de significación que los configuraron y los configuran como 
símbolos de la escuela pública, qué cargas conllevan, sobre qué inclusiones y exclusiones se fundan, y en alguna medida reproducen injusticias viejas y nuevas. Pensar, como lo hicieron muchos educadores, que el guardapolvo resuelve por sí sólo los complejos problemas de la inclusión y exclusión sociales, es creer que la ficción de equivalencia se ha realizado, olvidando el lado oscuro de esta misma ficción que ha implicado la constitución de jerarquías, la cristalización del otro como inferior o incapaz, y la negación de la diversidad y el pluralismo como fundamento de una vida democrática.

\section{NOTAS FINALES: CONFRONTANDO LOS RESTOS DEL NAUFRAGIO EN LA POSMODERNIDAD LATINOAMERICANA}

Los españoles Colom y Mèlich ( 1994) nos convocan a enfrentarnos con los "restos del naufragio", como ellos llaman a la pérdida de la confianza ciega en la escolaridad, entendiendo que la sociedad ha cambiado profundamente, y que la escuela también tiene que cambiar, si no quiere quedar girando en el vacío. La irrupción de la posmodernidad con sus nuevas condiciones vitales y culturales, con su translocación de las certidumbres e identidades, ha implicado un movimiento que disturba profundamente a la escuela como institución moderna.

Entre los restos del naufragio, está la cuestión de la inclusión y la ilustración como proyectos sociales. Revisar los relatos sobre la inclusión y la exclusión nos parece todavía urgente hoy, en que la cuestión del acceso a la escolaridad está garantizado para una buena parte de la población pero la cuestión de la exclusión parece haberse desplazado al interior de la escuela. La exclusión sigue operando en la clasificación de la población escolar en términos de indisciplinados, violentos, desertores, desmotivados, "chicos-problema" como se los llama en Argentina. Hay casos más extremos y casos menos extremos, pero todos adquieren dramatismo a la hora de considerar las historias y trayectorias individuales y de pensar como la experiencia escolar marco, o dejó de marcar, la experiencia vital y las oportunidades futuras de muchos niños y niñas.

Nos parece todavía más urgente esta revisión, cuando la respuesta que la escuela articula frente a estos excluídos se limita a pensar nuevas estrategias de motivación, nuevos tests para detectar y clasificar los comportamientos, o nuevas técnicas de segregación de quienes emergen como conflictivos. La hegemonía de la psicología educacional, en una versión particular que esencializa estos desarrollos, ha despolitizado y deshistorizado dramáticamente la cuestión de la inclusión y la 
exclusión, planteando que lo único que debemos hacer los educadores es encontrar soluciones técnicas y diseños institucionales o curriculares actualizados. Sin embargo, como espero haber dejado en claro en esta ponencia, la inclusión y la exclusión son procesos históricos y políticos, que exigen de nosotros una responsabilidad: la de tomar decisiones sobre como intervendremos en la configuración de la sociedad y la de aceptar las consecuencias y los riesgos de asumir esa responsabilidad. Cuando hablo de "riesgos", lo hago con plena intención de señalar sus peligros. Todo proyecto educativo de transmisión del saber está imbricado en relaciones de poder, que definen qué es lo que transmitimos y cómo lo transmitimos; en tanto relación de poder, implica un grado de violencia y de imposición sobre otro, y corre el riesgo de cometer injusticias. Quienes creen que la ficción de equivalencia puede realizarse en forma completa y transparente olvidan que toda inclusión supone exclusiones, más o menos dramáticas y más o menos cristalizadas. En todo caso, se trata de pensar cuáles son las formas de inclusión que ayudaran a resolver algunas de las injusticias actuales, y cómo pueden pensarse mecanismos e instituciones que eviten cristalizarlas permanentemente y las conviertan en una alteridad total y absoluta. Debemos, como educadores y como ciudadanos, asumir responsabilidades por las injusticias que se provocarán, de sopesar posibilidades y de tener en cuenta sus efectos. Se me ocurre que una manera de hacerlo es repensar a nuestras sociedades en términos más abiertos y móviles, con una vida democrática basada en la diversidad y la pluralidad de identidades, a la par que con derechos igualitarios para todos.

En un trabajo anterior, señalamos que en estas nuevas condiciones de vida posmodernas es necesario repensar el lugar de la escuela en el mundo, reemplazando el extendido optimismo pedagógico por un optimismo local, puntual, que encuentre márgenes de libertad y oportunidades para desarrollar otro tipo de relaciones pedagógicas (Caruso, Dussel, 1996). Hoy sigue siendo importante convocarnos a pensar cómo pueden redefinirse la inclusión y la exclusión desde este optimismo local, concibiendo a la escuela como una oportunidad de dejar marcas en los sujetos de una sociedad un poco más justa e igualitaria, y también de una cultura que valora la diferencia y la promueve como base del enriquecimiento personal y social.

\section{BIBLIOGRAFIA}

BERNAL, M. Black athena: the afroasiatic roots of classical civilization. New Brunswick: Rutgers University Press, 1987. 
BIRGIN, A. et al. Análisis del desarrollo curricular. Provincia de Mendoza: Flacso; 1994. [Informe Final de Investigación]

BLUMHAGEN, D. The Doctor's white coat: the image of the phyisician in modern America. Annals of Internal Medicine, n.9 I, p. I | | - | 16, 1979.

BOURDIEU, P. La Distinción: criterios y bases sociales del gusto. Madrid: Taurus Humanidades, 1988.

BRASLAVSKY, C. Los Usos de la historia en los libros de texto para las escuelas primarias argentinas. Buenos Aires: Flacso, 1993. [Serie: Documentos e informes de investigación, 144]

BRITZMAN, D. The Terrible problem of knowing thyself: towards a poststructural account of teacher identity. Journal of Curriculum Theorizing, n.9, p.23-46, 1992.

BUTLER, J. Bodies that matter: on the discursive limits of "sex". New York, London: Routlegde, 1993.

CALVO, F. M. Principios generadores como base de la instrucción y educación. Boletín de Ensenanza y Administración Escolar, v.5, n.3, p. 67-70, mar. 1900.

CARUSO, M.; DUSSEL, I. De Sarmiento a los Simpsons: conceptos para pensar la educación contemporánea. Buenos Aires: Kapelusz, 1996.

CAVAROZZI, M. Elementos para una caracterización del capitalismo oligárquico. Revista Mexicana de Sociología, v.78. n.4, 1978.

COLOM, A.; MÈLICH, J. Después de la modernidad: nuevas filosofías de la educación. Barcelona: Paidós, 1994.

CONNOLLY, W. Identity difference: democratic negotiations of political paradox. Ithaca, London: Cornell University Press, 1991.

CORRIGAN, P. The Making of the boy: meditations on what grammar school did with, to, and for my body. Journal of Education, v. I70, n.3, p. |42-161, 1988.

CHAVARRÍA, J. C. La Escuela normal y la cultura argentina. Buenos Aires, 1945.

CHEVALLIER, P.; GROSPERRIN, B. L'Enseignement français de la révolution à nos jours. Paris: Mouton, 197I. v. 2 : Documents.

CHIARAMONTE, J. C. Formas de identidad en el Río de la Plata ( 8 | 0- | 850). Boletín del Instituto de Historia Argentina, v. I, n.2, p. 13-30, 1989.

DONALD, J. Sentimental education: schooling, popular culture and everyday life. London; New York: Verso, 1992.

DUSCHATZKY, S. La Escuela como frontera: reflexiones sobre la experiencia escolar de jóvenes de sectores populares. Buenos Aires: Paidós, 1999. 
DUSSEL, I. Grupo de investigación "Políticas y reformas educativas". Papeles, Granada, Universidad de Granada, v. I, n. I, p.75-96, 2003.

Historias de guardapolvos y uniformes: sobre cuerpos, normas e identidades en la escuela. In: GVIRTZ, S. (ed.) Rutina o cotidianeidad: herramientas para pensar el día a día. Buenos Aires: Santillana, 2000.

Pedagogía y burocracia: notas sobre la historia de los inspectores. Revista Argentina de Educación, n.21, p.55-82, 1996.

Profile of famous educators: Víctor Mercante. Prospects, Paris, Unesco, v. 26, n. 2, p.415-431, 1996a.

School uniforms and the disciplining of appearances: towards a history of the regulation of bodies in modern educational systems. In: POPKEWITZ, T.S.; FRANKLIN, B.; PEREYRA, M. Cultural history and critical studies of education: dissenting essays. New York: Routledge, 200. p.207-24l.

DUSSEL, I.; CARUSO M. La Invención pedagógica del aula: una genealogía de las formas de enseñar. Santillana: Buenos Aires, 2000.

EWALD, F. Norms, discipline, and the law. Representations, n.30, p. 138-161, 1990.

FOUCAULT, M. Vigilar y castigar. el nacimiento de la prision. Mexico D.F.: Siglo XXI, 1977. GAGLIANO, R. Educación, política y cultura adolescente (1955-1970). In: PUIGGRÓS, A. (comp.) Dictaduras y utopías en la historia reciente de la educación argentina (1955-1983). Buenos Aires: Galerna, 1997. p.321-350.

GARCÍA CANCLINI, N. Culturas híbridas. México: Conaculta, Grijalbo, 1990.

GORELIK, A. La Grilla y el parque: espacio urbano y cultura urbana en Buenos Aires, 1887 1936. Buenos Aires: Universidad Nacional de Quilmes, 1998.

GOULD, S. The Mismeasure of man. London: Penguin Books, 1981.

GROSZ, E. Space, time, and perversion: essays on the politics of bodies. New York; London: Routledge, 1995.

HABERMAS, J. Historia y crítica de la opinión pública: la transformación estructural de la vida pública. 2. ed. México; Barcelona: Gustavo Gili, 1990.

HALL, S. Minimal selves. In: BAKER, H., JR.; DIAWARA, M. Y; LINDENBORG, R. (eds.) Black british cultural studies. a reader. Chicago; London: The University of Chicago Press, 1996. p.|14-119.

HAMILTON, D. Towards a theory of schooling. London; New York: Falmer Press, 1989. 
HOUSTON LUIGGI, A. Sesenta y cinco valientes: Sarmiento y las maestras norteamericanas. Buenos Aires: Agora, 1959.

HUNTER, I. Repensar la escuela: subjetividad, burocracia y crítica. Barcelona: PomaresCorredor, 1998.

JOSEPH, N. Uniforms and non-uniforms: communication through clothing. New York; Westport: Greenwood Press, 1986.

KLIEBARD, H. The Struggle for the american curriculum (I 893-1958). New York; London: Routledge, 1986.

LATOUR, B. The Pasteurization of France. Cambridge, MA; London: Harvard University Press, 1988.

LOPES LOURO, G. O Corpo educado: pedagogias da sexualidade. Belo Horizonte: Autentica, 1999. p.7-34: Pedagogias da sexualidade.

LUGONES, L. Didáctica. Buenos Aires: Talleres de la Penitenciaría Nacional, I9l 5.

MERCANTE, V. Charlas pedagógicas. Buenos Aires: R. Gleizer, 1927.

MIDDLETON, S. Disciplining sexuality: Foucault, life histories, and education. New York; London: Teachers' College Press, 1998.

MIGNOLO, W. The Darker side of the renaissance: literacy, territoriality, \& colonization. Ann Arbor; The University of Michigan Press, 1995.

Local histories/global designs: coloniality, subaltern knowledges, and border thinking. Princeton: Princeton University Press, 2000.

NIQUE, CH.; LELIÈVRE, C. La République n'éduquera plus. la fin du mythe Ferry. Paris: Plon, 1993.

PAOLETTI, J.; KREGLOH, C. The Children's department. In: KIDWELL, B. C.; STEELE, V. (eds.) Men and women dressing the part. Washington, D.C.: Smithsonian Institution Press, 1989. p. 22-41.

PERROT, P. La Richesse cachée: pour une génealogie de l'austerité des apparences. Communications, n.46, p.157-179, 1987.

PINEAU, P. La Escolarización de la provincia de Buenos Aires (1875-1930): una versión posible. Buenos Aires: Flacso/CBC-UBA, 1997.

POPKEWITZ, Th. S. A Political sociology of educational reform. New York: Teachers' College Press, 1991.

The Strugg/e for the sout. the spatial politics of educational reform. New York; London: Teachers'College Press, 1998. 
PUIGGRÓS, A. A. Qué pasó en la educación argentina: desde la conquista hasta el menemismo. Buenos Aires: Kapelusz, 1996.

Sujetos, disciplina y curriculum en los orígenes del sistema educativo argentino (|885-1916). Buenos Aires: Galerna, 1990.

ROMERO, L.A.; GUTIÉRREZ, L. Ciudadanía política y ciudadanía social: los sectores populares en Buenos Aires, 1912-1955. Indice, n.5, p. 12-25, 1992.

SÁBATO, H. Citizenship, political participation and the formation of the public sphere in Buenos Aires: 1850s-1880s. Past and Present, n. 136, p. 139-163, aug. 1992.

SANTONI RUGIU, A. Storia sociale dell'educazione. Milano: Principato, 1980.

SARLO, B. B. Cabezas rapadas y cintas argentinas. Prismas: Revista de Historia Intelectual, v.l, n. I, p.|87-191, 1997.

A Writer on the edge. London: Verso, 1993.

SCHWARZ, R. Ao Vencedor as batatas. São Paulo: Duas Cidades, 1977.

SENET, R. Apuntes de pedagogía adaptados al programa de ler: año normal. Buenos Aires: Cabaut y Cía., 1918.

SYNOTT, J. ; SYMES, C. The Genealogy of the school: an iconography of badges and mottoes. British Journal of Sociology of Education, v. I6, n. 2, p. I39- I53, 1995.

TEDESCO, J. C. Educación y sociedad en la Argentina ( 880 - 1945). Buenos Aires: Hachette, 1986.

TRAVERSA, O. Cuerpos de papel: figuraciones del cuerpo en la prensa, 19 I 8- 1940. Barcelona: Gedisa, 1997.

TYACK, D.; CUBAN, L. Tinkering towards utopia: a century of public school reform. Cambridge, London: Harvard University Press, 1995.

VILANOVA RUBIAS, M.; MORENO JULIÀ, X. Atlas de la evolución del analfabetismo en España de 1887 a 198/. Madrid: Cide, 1990.

Recebido em: março 2004

Aprovado para publicação em: abril 2004 